\title{
Association between quinolone use in food animals and gonococcal resistance to ciprofloxacin: an ecological study
}

Natalia Gonzalez

Said Abdellati

Sheeba Manoharan-Basil

Chris Kenyon ${ }^{1,2^{*}}$

${ }^{1} \mathrm{HIV} / \mathrm{STI}$ Unit, Institute of Tropical Medicine, Antwerp, Belgium; ${ }^{2}$ Division of Infectious Diseases and HIV Medicine, University of Cape Town, Anzio Road, Observatory 7700, South Africa

${ }^{*}$ Corresponding author. HIV/STI Unit, Institute of Tropical Medicine, Antwerp, 2000, Belgium. Tel: +32 3 2480796; Fax: +32 3 2480831; E-mail: ckenyon@itg.be

Running title: Fluoroquinolone minimum selection concentration for $N$. gonorrhoeae

Word count: Text: 1659 words, Abstract: 27

\section{Abstract}




\section{Background}

Concentrations of fluoroquinolones up to 200 -fold lower than the MIC have been shown to be able to select for antimicrobial resistance in E. coli and Salmonella spp. (the minimum selection concentration - MSC). We aimed to i) establish what the ciprofloxacin MSC is for Neisseria gonorrhoeae and ii) Assess at a country level if the prevalence of gonococcal ciprofloxacin resistance is associated with the concentration of quinolones used in food animal production (an important determinant of long-term low dose ciprofloxacin exposures in humans).

\section{Methods}

i). To assess if sub-inhibitory ciprofloxacin concentrations could select for de novo generated resistant mutants, susceptible WHO-P was serially passaged at 1, 1/10, $1 / 100$ and $1 / 1000$ of the ciprofloxacin MIC of WHO-P $(0.004 \mathrm{mg} / \mathrm{L})$ on GC agar plates. ii) Spearman's correlation was used to assess the association between the prevalence of ciprofloxacin resistance in N. gonorrhoeae and the two independent variables - quinolone use for animals and quinolone consumption by humans.

\section{Results}

Ciprofloxacin concentrations as low as $1 / 1000$ of the MIC of WHO-P were able to select for ciprofloxacin resistance. The prevalence of ciprofloxacin resistance in $N$. gonorrhoeae was positively associated with quinolone use for food animals $(\rho=0.47$; $P=0.004 ; N=34)$.

\section{Conclusion}


bioRxiv preprint doi: https://doi.org/10.1101/2021.06.03.446933; this version posted September 10, 2021. The copyright holder for this preprint (which was not certified by peer review) is the author/funder, who has granted bioRxiv a license to display the preprint in perpetuity. It is made available under aCC-BY-NC-ND 4.0 International license.

Further individual level research is required to assess if low doses of ciprofloxacin from ingested foodstuffs are able to select for ciprofloxacin resistance in $\mathrm{N}$. gonorrhoeae and other species.

Keywords: N. gonorrhoeae, antimicrobial consumption, AMR, resistance, quinolone, one-health 


\section{Introduction}

Why has gonococcal resistance to fluoroquinolones emerged so explosively in East Asia? The prevalence of ciprofloxacin resistance in China, for example, increased from $10 \%$ to $95 \%$ between 1996 and 2003 [1]. In comparison, the country-level median prevalence of ciprofloxacin resistance in 2009 was $24 \%$ in the Americas and $6 \%$ in Africa [2]. Whilst differences in the intensity of exposure to fluoroquinolones likely play a key role in explaining these differences in resistance, it is not clear what pathways are most important. Quinolones used to treat $N$. gonorrhoeae can select for antimicrobial resistance (AMR) directly (direct selection). Because $N$. gonorrhoeae is asymptomatic for the majority of the time it circulates in a population, quinolones used for other indications can also select for AMR (bystander selection) [3]. N. gonorrhoeae can also acquire resistance conferring genes from commensal Neisseria [4]. Quinolone used for any indication could select for ciprofloxacin resistance in commensals and subsequently in $N$. gonorrhoeae via this indirect selection pathway $[5,6]$. Studies have provided support for each of these pathways in the genesis of gonococcal AMR [4-6]. In particular, a number of studies have established that country level consumption of quinolones is a predictor of ciprofloxacin resistance [2, 3]. Certain Asian countries such as China, Malaysia and the Philippines have been noted to be outliers in these analyses [2]. In 2009, for example, these 3 countries had close to $100 \%$ resistance to ciprofloxacin, but all consumed less than half the volume of quinolones consumed by the United States where less than $10 \%$ of gonococcal isolates were resistant to ciprofloxacin [2].

There is also an increasing body of evidence to suggest that quinolone resistance in N. gonorrhoeae in Asia and elsewhere is part of a syndemic of resistance affecting a 
range of gram negatives including Escherichia coli and Pseudomonas spp. [7]. Further evidence for the syndemic perspective comes from studies which show that the prevalence of quinolone resistance is considerably higher (up to 16-fold higher) in a number of gram negatives in Asia than in Europe and the Americas [8-11]. Between 1998 and 2009, for example the prevalence of ciprofloxacin resistance in Shigella increased from $0 \%$ to $29 \%$ in Asia compared to $0 \%$ to $0.6 \%$ in EuropeAmerica [8]. This syndemic of quinolone resistance may include $N$. meningitidis and various species of commensal Neisseria [12]. Recent studies from Shanghai, for example, have found the prevalence of ciprofloxacin resistance to be $99 \%$ in $N$. gonorrhoeae, $100 \%$ in commensal Neisseria and $66 \%$ in $N$. meningitidis $[6,13,14]$. These findings suggest that quinolone exposure other than that used for human infections, may be playing a role in the genesis and spread of quinolone resistance. One such possibility is quinolones used for animal husbandry.

Quinolone use in animals has been linked to AMR in a number of gram-negative pathogens circulating in humans $[15,16]$. This use of quinolones could induce resistance in $N$. gonorrhoeae directly or indirectly. Direct selection on $N$. gonorrhoeae would occur via human ingestion of quinolone residues in meat or water/soil contaminated by animal manure [17]. Quinolones have been found to show very low biodegradability in the environment $[17,18]$. Selection could also occur indirectly where quinolones select for resistance in commensal Neisseria which is then transformed into $N$. gonorrhoeae. Commensal Neisseria have been found in the resident microbiomes of a range of food animals including chickens, cows, sheep and goats [19-22]. The selection of quinolone resistance in commensal Neisseria could thus occur in the animals or humans. Of note the indirect pathway 
has been shown to be important in the genesis and spread of cephalosporin resistance (mainly via the spread of plasmids) in various gram-negative bacteria such as E. coli [15].

An important finding in this field is that antimicrobial concentrations up to 230 -fold lower than the minimal inhibitory concentration (MIC) are capable of inducing AMR in bacteria such as E. coli and Salmonella enterica spp. [23, 24]. Whilst such experiments have not been conducted in Neisseria spp., concentrations of ciprofloxacin as low as $0.1 \mu \mathrm{g} / \mathrm{L}$ have been shown to able to select for resistance in other gram negative bacteria [23, 25]. Quinolone concentrations in meat, water and environmental samples have been found to far exceed this threshold in a number of locales. For example, studies have found that the mean concentration of ciprofloxacin in samples of milk, eggs, and edible fish in China to be $8.5 \mu \mathrm{g} / \mathrm{L}, 16.8$ $\mu \mathrm{g} / \mathrm{kg}$ and $331.7 \mu \mathrm{g} / \mathrm{kg}$ respectively (Fig. 1)[26-28]. Not even drinking water from taps (median quinolone concentration $0.270 \mu \mathrm{g} / \mathrm{L}$ ) [29] and bottled water [30] in China is free of quinolones and other antimicrobials.

These findings provided the motivation to for the two aims of this study: i) Assess the MSC of $N$. gonorrhoeae. ii) Assess at a country level if the prevalence of gonococcal ciprofloxacin resistance is associated with the concentration of quinolones used in food animal production.

\section{Methods}

\section{A. In-vitro determination of minimum selection concentrations (MSC)}




\section{Bacterial strains and growth conditions}

The WHO-P reference strain of $N$. gonorrhoeae was used for all experiments. The ciprofloxacin resistant strain was selected for by culturing on gonococcal (GC) agar plates supplemented with ciprofloxacin $0.008 \mathrm{mg} / \mathrm{L}(4 \times \mathrm{MIC})$. After 24 hours the MIC of this strain attained $0.125 \mathrm{mg} / \mathrm{L}$ and whole genome sequencing confirmed the acquisition of the S91F resistance associated mutation in gyrA.

All experiments were conducted using GC broth supplemented with IsoVitaleX ${ }^{\mathrm{TM}}$ (1\%) for liquid or solid media. Strains were grown at $36^{\circ} \mathrm{C}$, in $5 \% \mathrm{CO} 2$.

\section{MSC Determination}

There are two important components of the MSC: i) The minimum concentration of an antimicrobial at which one can select for de-novo resistance $\left(\mathrm{MSC}_{\text {denovo }}\right)$; ii) The lowest antimicrobial concentration that selects for a resistant- compared to a susceptible-strain $\left(\mathrm{MSC}_{\text {select }}\right)[31,32]$. The methodology to assess the $\mathrm{MSC}_{\text {select }}$ and the $\mathrm{MSC}_{\text {denovo }}$ was based on that used by Gullberg et al [23, 25].

\section{MSC $_{\text {denovo }}$}

To assess if sub-inhibitory ciprofloxacin concentrations could select for de novo generated resistant mutants, susceptible WHO-P was serially passaged at 1, 1/10, $1 / 100$ and $1 / 1000$ of the ciprofloxacin MIC of WHO-P $(0.004 \mathrm{mg} / \mathrm{L})$ on GC agar plates. Identical control experiments were conducted with plates containing no ciprofloxacin. They were passaged at the same concentration of ciprofloxacin every 24 hours for 7 days. The number of colonies of WHO-P with reduced susceptibility and resistance to ciprofloxacin was established by plating $600 \mu \mathrm{L}$ from a Phosphate 
Buffered Saline (PBS) solution containing the full growth from each experiment onto three GC agar plates: i) no ciprofloxacin, ii) ciprofloxacin concentration of $0.016 \mathrm{mg} / \mathrm{L}$ (reduced susceptibility) and iii) ciprofloxacin $0.06 \mathrm{mg} / \mathrm{L}$ (EUCAST breakpoint for ciprofloxacin resistance). The number of colonies was counted after 24 hours incubation. The lowest ciprofloxacin concentration that resulted in growth of WHO-P in the ciprofloxacin $0.06 \mathrm{mg} / \mathrm{L}$ plates was defined as the $\mathrm{MSC}_{\text {denovo. }}$. Each experiment was conducted in quadruplicate. A subset of the colonies were replated on plates with the same concentration of ciprofloxacin to confirm that they were resistant.

\section{$\mathrm{MSC}_{\text {select }}$}

Growth rates were measured in standard $15 \mathrm{ml}$ vials in the NGmorbidostat whose construction and optimization for the culture of $N$. gonorrhoeae has been described elsewhere [33, 34]. The vials were continuously stirred at a speed of 200 rotations per minute (rpm) via a magnetic stirrer. The optic density (OD) of each vial was measured once a minute via a system of infrared light emitting diodes and photodetectors and recorded in an automated fashion (Matlab R2015b).

The growth rates of the susceptible and resistant $N$. gonorrhoeae at $36^{\circ} \mathrm{C}$ in $\mathrm{GC}$ broth, were assessed in vials containing the following ciprofloxacin concentrations: 0 , $1,1 / 10,1 / 100$ and $1 / 1000$ times of the ciprofloxacin MIC of WHO-P $(0.004 \mathrm{mg} / \mathrm{L})$.

Each vial was inoculated with $100 \mu \mathrm{L}$ of 4 McFarland $N$. gonorrhoeae, and the cultures were grown for 24 hours with continuous stirring. The relative growth rates at each concentration of ciprofloxacin were calculated as the observed growth rate of the strain divided by the growth rate of the same strain without ciprofloxacin. This experiment was conducted in triplicate. 
Growthcurver was used to summarize the growth characteristics of each vial [35]. Growthcurver fits a basic form of the logistic equation common in ecology and evolution to experimentally-obtained growth curve data. It provides a number of summary measures to describe growth curves. We used two of these to calculate the $\mathrm{MSC}_{\text {select }}$

1. Growth rate. The intrinsic growth rate of the population, $r$, is the growth rate that would occur if there were no restrictions imposed on growth. Growthcurver uses the non-linear least-squares Levenberg-Marquardt algorithm to determine $r$.

2. Area under the curve. Growthcurver calculates the area under the logistic curve $(A \cup C)$. This integrates information from the carrying capacity, growth rate and the population size at time 0.

The $\mathrm{MSC}_{\text {select }}$ was calculated as the point where the relative growth curves of the ciprofloxacin resistant and susceptible Neisseria gonorrhoeae crossed [25]. For the calculation of the $\mathrm{MSC}_{\text {select, }}$, we calculated the average value obtained from the individual experiments.

\section{B. Ecological association between quinolone use and ciprofloxacin MICs}


Quinolone use for animal food production data. We obtained the country level consumption of quinolones for animal food production in the year 2013 from a systematic review on this topic performed by Broeckel et al. [36]. This study calculated the volume of antimicrobials (in tons) by class of antimicrobial in 38 countries in the year 2013. Four categories of animals were included: chicken, cattle, pigs and small ruminants (sheep and goats), which together account for the overwhelming majority of terrestrial animals raised for food $[15,36]$.

We used this data to calculate the number of milligrams of quinolones used for animal food production/population correction unit (PCU) (a kilogram of animal product) in the year 2013. The data for the tonnage of food animals produced per country and year in the year 2013 was taken from the Food and Agriculture Organization estimates (http://www.fao.org/faostat/en/?\#data/).

Quinolone consumption in humans. Data from IQVIA were used as a measure of national antimicrobial drug consumption. IQVIA uses national sample surveys that are performed by pharmaceutical sales distribution channels to estimate antimicrobial consumption from the volume of antibiotics sold in retail and hospital pharmacies. The sales estimates from this sample are projected with use of an algorithm developed by IQVIA to approximate total volumes for sales and consumption. Quinolone consumption (moxifloxacin, ciprofloxacin, gemifloxacin, ofloxacin, levofloxacin, lomefloxacin, norfloxacin, enoxacin, gatifloxacin, trovafloxacin, sparfloxacin) estimates are reported as the number of standard doses (a dose is classified as a pill, capsule, or ampoule) per 1000 population per year [2]. 
N. gonorrhoeae ciprofloxacin resistance data. The percent of isolates per country that were resistant to ciprofloxacin in the year 2014 (the year following the quinolone consumption variables) was taken from the WHO Global Gonococcal Antimicrobial Surveillance Programme (GASP; https://www.who.int/data/gho/data/indicators). GASP is a collaborative global network of regional and subregional reference laboratories that monitors gonococcal AMR in participating countries. The full GASP methodology, including suggested sampling strategy, laboratory techniques, external quality assurance, and internal quality control mechanisms has been published elsewhere [37]. GASP uses a minimum inhibitory concentration (MIC) breakpoint of $1 \mu \mathrm{g} / \mathrm{ml}$ to define resistance to ciprofloxacin, which was therefore the definition of ciprofloxacin resistance we used [37]. In the case of 4 countries, data was not available for the year 2014. We used the data for the first subsequent year with available data - 2016 (Czechia, Luxembourg) and 2017 (Finland, Switzerland).

\section{Statistical analysis}

Spearman's correlation was used to assess the association between the prevalence of ciprofloxacin resistance in $N$. gonorrhoeae and the two independent variables quinolone use for animals and quinolone consumption by humans. Linear regression was used to assess the country-level association between the percent of $N$. gonorrhoeae isolates with ciprofloxacin resistance and the two independent variables in 3 models. We started by assessing the association between ciprofloxacin resistance and quinolone consumption in humans (Model-1). We then assessed the association between ciprofloxacin resistance and quinolone use in animals (Model2). Finally in Model-3 we evaluated the effect of both independent variables on 
ciprofloxacin resistance. Stata 16.0 was used for all analyses. A p-value of $<0.05$ was considered statistically significant.

\section{Results}

\section{Minimum selection concentration}

\section{MSC $_{\text {denovo }}$}

Ciprofloxacin concentrations as low as $0.004 \mu \mathrm{g} / \mathrm{L}\left(1 / 1000^{\text {th }}\right.$ the $\left.\mathrm{MIC}\right)$ were able to induce resistance to ciprofloxacin (the minimum selection concentration; Fig. 1; Supplementary Table1). This occurred in only one colony in one of four experiments at $0.004 \mu \mathrm{g} / \mathrm{L}$. Higher concentrations of ciprofloxacin resulted in a higher number of ciprofloxacin resistant colonies. Unsurprisingly, the number of colonies with reduced susceptibility to ciprofloxacin was generally higher than the number with ciprofloxacin resistance.

\section{MSC $_{\text {select }}$}

The mean $\mathrm{MSC}_{\text {select }}$ obtained by the AUC ratio method (mean $0.007 \mathrm{mg} / \mathrm{L}$, range $0.001-0.019 \mathrm{mg} / \mathrm{L})$ was considerably lower than that obtained by the growth rate method (mean 0.413 mg/L, range 0.023-0.98mg/L; Fig.1; Supplementary Table 2).

\section{Ecological association between quinolone consumption and ciprofloxacin resistance}


No quinolone consumption data was available for two countries (Iran and Nepal). There was considerable variation in quinolone use for food animals in the 36 countries with data (median $1.9 \mathrm{mg}$ quinolones/PCU (IQR 0.7-6.6 mg/PCU; Supplementary Table 2). Quinolone exposure in China was higher than all other countries (261.2 mg/PCU).

The prevalence of ciprofloxacin resistance in $N$. gonorrhoeae was positively associated with quinolone use for food animals $(\rho=0.47 ; P=0.004 ; N=34)$ but not quinolone consumption in humans $(\rho=0.31 ; P=0.097 ; N=30)$.

The model that combined quinolone use in food and humans was a better predictor of gonococcal ciprofloxacin resistance $\left(R^{2}=0.30\right.$; Model 3$)$ than the models that only included either quinolone use in animals or humans $\left(R^{2}=0.14\right.$ [Model 2] and $R^{2}=0.07$ [Model 1], respectively; Table 2).

\section{Discussion}

We found that the gonococcal MSC for ciprofloxacin was lower than that for any other bacteria on record $[23,25]$. In particular the $\mathrm{MSC}_{\text {denovo }}(0.004 \mu \mathrm{g} / \mathrm{L})$ was considerably lower than quinolone concentrations found in foodstuffs such as meat products, milk and water in China and elsewhere (Fig. 3) [26-30]. The consumption of foods with high quinolone concentrations has been found to be associated with high urinary and faecal concentrations of quinolones in humans [38-41]. For example, a study from South Korea found that high urinary excretion of enrofloxacin and ciprofloxacin in the general population were strongly associated with consumption of beef, chicken and dairy products [38]. Likewise, a large study of the 
general population in 3 regions of China found ciprofloxacin, enrofloxacin and ofloxacin in the faeces of $67 \%, 30 \%$ and $57 \%$ of individuals [41]. The authors attributed the high median concentration of quinolones (median $20 \mu \mathrm{g} / \mathrm{kg}$ ), in large part, to the ingestion of veterinary antimicrobials in food [42]. Reducing consumption of these foodstuffs has also been found to result in a reduction of urinary quinolone concentrations [42]. The problem of high antimicrobial concentrations in human food is not limited to Asian countries. In European countries, food animals consume a greater mass of antimicrobials per kilogram per year than humans do [43]. Furthermore, studies from Europe have shown AMC in animals is independently associated with AMR in bacterial species colonizing and infecting humans [43].

These findings generate the hypothesis that quinolone concentrations in food may play a role in the genesis of quinolone resistance in bacteria such as $N$. gonorrhoeae. We found supportive evidence at a country level - quinolone consumption for animal husbandry was positively associated with the prevalence of ciprofloxacin resistance in $N$. gonorrhoeae. Furthermore, the combination of quinolone consumption in humans and food animals provided the best prediction of ciprofloxacin resistance. These findings could explain a number of anomalies that have been noted in the global epidemiology of quinolone resistance in $N$. gonorrhoeae and other Neisseria. China has noted to be an outlier in the generally positive associations that have been found between country-level quinolone consumption in humans and resistance [2]. Quinolone consumption by humans is not in the top quintile but the prevalence of quinolone resistance in $N$. gonorrhoeae as well as $N$. meningitidis and commensal Neisseria is one of the highest in the world $[2,6,37,44]$. 
Our estimates of the $\mathrm{MSC}_{\text {select }}$ derived from the two methods differed considerably. The estimate of the $\mathrm{MSC}_{\text {select }}$ derived from the AUC ratio method was however similar to the $\mathrm{MSC}_{\text {denovo. }} \mathrm{A}$ number of factors have been shown experimentally to affect the MSC. For example, MSCs have been shown to increase by 13- to 43-fold in complex environments such as those in the human body where bacteria are competing with one another and interacting with the hosts defenses [24, 45, 46]. The use of gfp labelling of the resistant and susceptible strains in direct competitive growth assays has also been shown to provide a more accurate way to ascertain the MSCselect [25].

Furthermore, in a real-world setting, human microbiota would be exposed to low dose antimicrobials intermittently (such as during and after eating) rather than continuously such as in our experiments. There are also large differences in antimicrobial penetration to different anatomical sites such as the oropharynx which we have not considered [47]. We also do not know if the effect of quinolones in food on Neisseria would act via direct contact with Neisseria in the mouth during mastication, in the colon during drug elimination or in the genital tract following absorption and distribution. We have also not considered the indirect-commensalpathway through which quinolones could select for AMR. Quinolones could select for resistance in commensals which could then be transferred to the pathogenic Neisseria via transformation $[6,48]$. These considerations imply that our estimates of the gonococcal MSC should be viewed as tentative. It is possible and even likely that the lowest concentration that can select for quinolone resistance in Neisseria species 
is contingent on a large number of cofactors such as microbiome community state types and individual human pharmacogenomic variations [24, 45, 46, 49].

For these reasons, we consider the calculation of an exact gonococcal ciprofloxacin MSC less important than establishing that it is considerably lower than the MIC. What is important is conducting experiments to ascertain if the concentrations of quinolones detected in contemporary foodstuffs can induce AMR in N. gonorrhoeae and other bacteria. Whilst it may to be difficult to do human challenge studies with $N$. gonorrhoeae, studies with commensal Neisseria may be possible. A further option would be to assess if food spiked with low concentrations of quinolones could induce AMR in Neisseria musculi, a colonic and oropharyngeal commensal of the common mouse, Mus musculus [50,51]. These studies may be of considerable use in determining what safe maximum residue limits (MRLs) of quinolones are in foodstuffs. Current European Commission and WHO/FAO guidelines for establishing MRLs evaluate the effect of antimicrobial residues on the toxicity towards a range of bacteria $[52,53]$. They do not however evaluate the effect of these residues on the genesis of AMR [46, 52, 54, 55].

There are also a number of limitations pertaining to the ecological study. These include the relatively small number of countries with available data, the lack of longitudinal data on quinolone consumption in animals and the absence of data on quinolone use for aquaculture. The epidemiology of resistance is complex and factors other than the amount of quinolones consumed may influence the level of quinolone resistance. These include consumption of other classes of antimicrobials, travel by humans and trade of live animals and meat [15]. 
Our results are thus best considered hypothesis generating. Further in-vivo experiments along the lines outlined above will be required to assess if quinolones in food residues are playing a role in the genesis of quinolone resistance in $N$. gonorrhoeae and related bacteria.

\section{Authors' contributions}

NG and CK conceptualized the study. NG and SA conducted the MSC experiments and CK was responsible for the acquisition, analysis and interpretation of the ecological analyses. All authors read and approved the final draft.

\section{Competing interests}

The authors declare that they have no competing interests.

\section{Funding}

Nil

\section{Acknowledgements}

Nil

\section{Consent for publication}

Not applicable 
Table 1. Linear regression models testing the country-level association between quinolone consumption in food animals/humans and the prevalence ciprofloxacin resistance expressed as a percentage [coefficients $(95 \%$ confidence intervals)]

\begin{tabular}{|l|l|l|l|}
\hline & Model 1 & Model 2 & Model 3 \\
\hline Quinolones Humans & $0.02 \quad(-0.007-$ & - & $0.2(0.001-0.046)^{*}$ \\
\hline Quinolones & $0.043)$ & & \\
\hline Food animals & - & $0.2(0.02-0.38)^{*}$ & $0.2(0.07-0.40)^{* *}$ \\
\hline $\mathrm{N}$ & 30 & 34 & 30 \\
\hline $\mathrm{R}^{2}$ & 0.07 & 0.14 & 0.30 \\
\hline * P-value $<0.05,{ }^{* *}$ P-value $<0.01$ & & \\
\hline
\end{tabular}


bioRxiv preprint doi: https://doi.org/10.1101/2021.06.03.446933; this version posted September 10, 2021. The copyright holder for this preprint (which was not certified by peer review) is the author/funder, who has granted bioRxiv a license to display the preprint in perpetuity. It is made available under aCC-BY-NC-ND 4.0 International license.

Figure 1. Mean number of colonies of $N$. gonorrhoeae grown for 7-days in different ciprofloxacin concentrations ranging from $1 \times \mathrm{MIC}$ to $1 / 1000^{\text {th }} \mathrm{MIC}$ of WHO-P, stratified according to their final growth in plates with no ciprofloxacin, $0.016 \mathrm{mg} / \mathrm{L}$ and $0.06 \mathrm{mg} / \mathrm{L}$. All the experiments were conducted in quadruplicate.

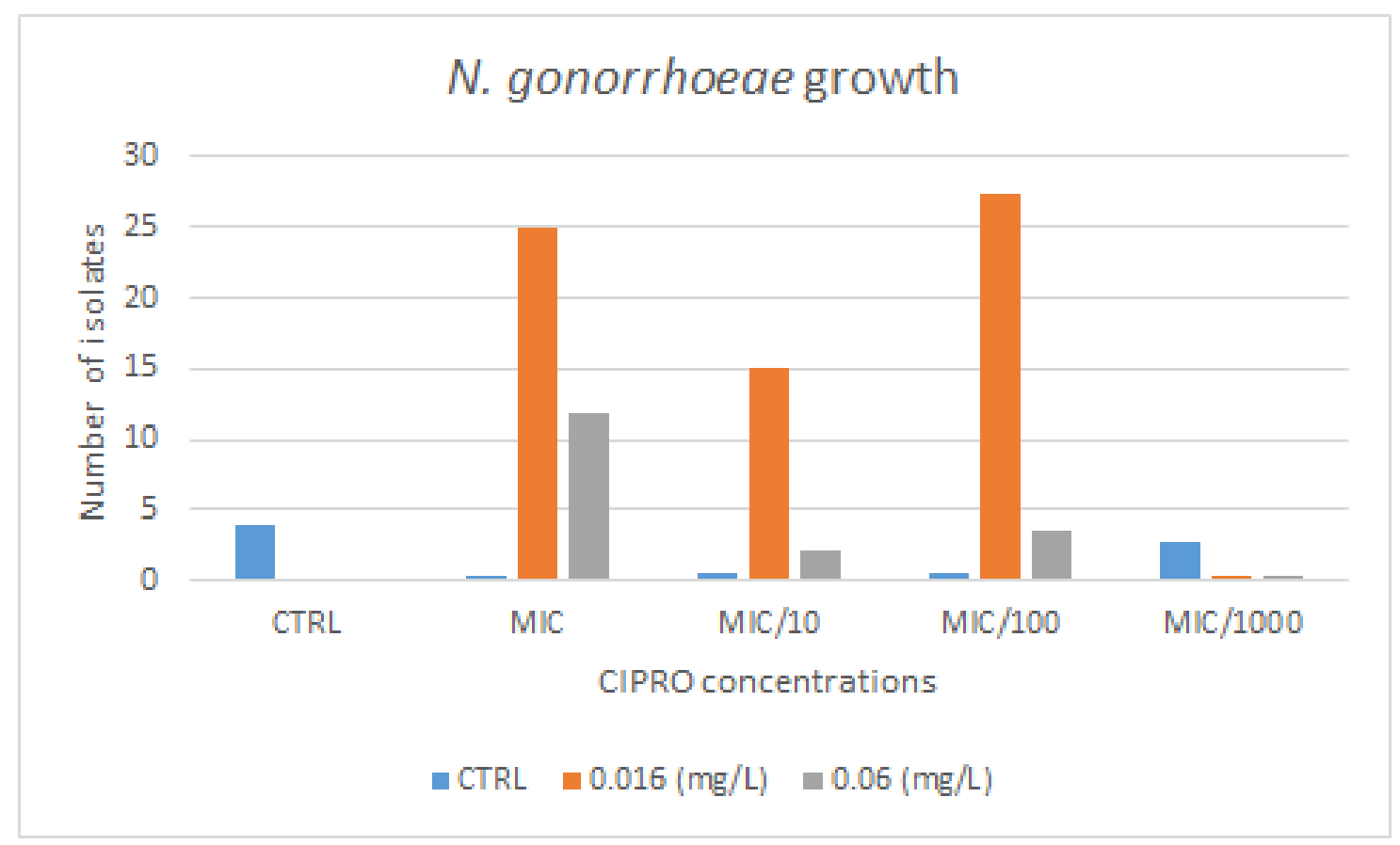


bioRxiv preprint doi: https://doi.org/10.1101/2021.06.03.446933; this version posted September 10, 2021. The copyright holder for this preprint (which was not certified by peer review) is the author/funder, who has granted bioRxiv a license to display the preprint in perpetuity. It is made available under aCC-BY-NC-ND 4.0 International license.

Figure 2. Growth rates as a function of ciprofloxacin (CIP) concentrations. The relative exponential growth rates $(A, B$ and $C)$ and $A U C$ Ratio $(D, E$ and $F)$ of $N$. gonorrhoeae WHO-P with (red) and without (blue) the gyrA S91F mutation conferring resistance to ciprofloxacin. The MSCselect is determined as the point where the blue and red lines intersect.

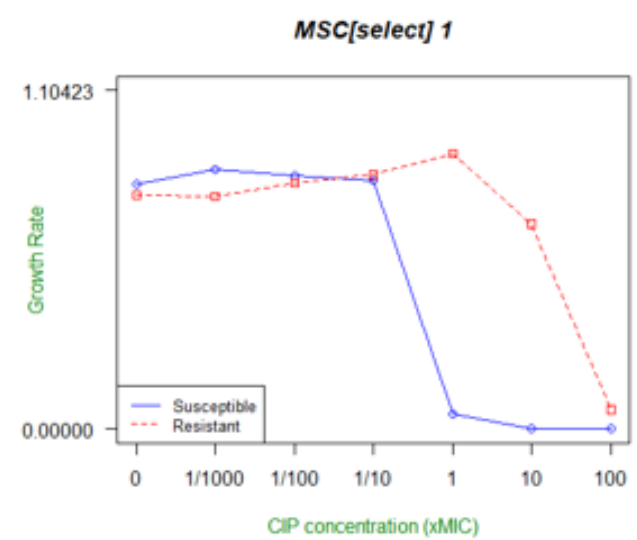

MSC[select] 2

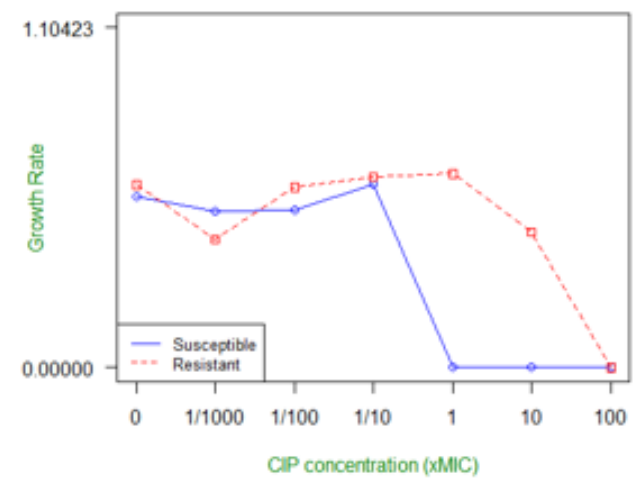

MSC[select] 3

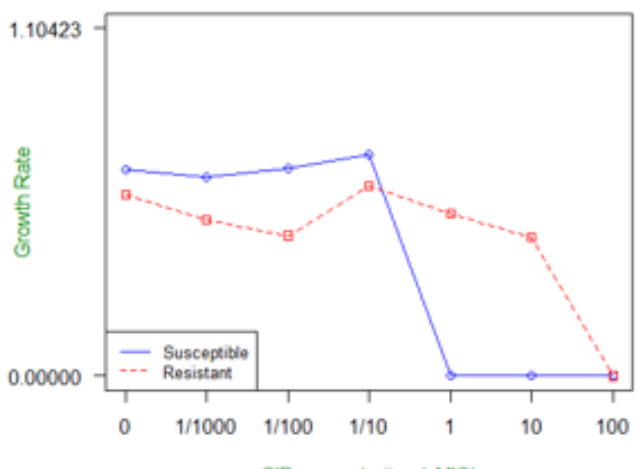

CIP concentration (xMIC)
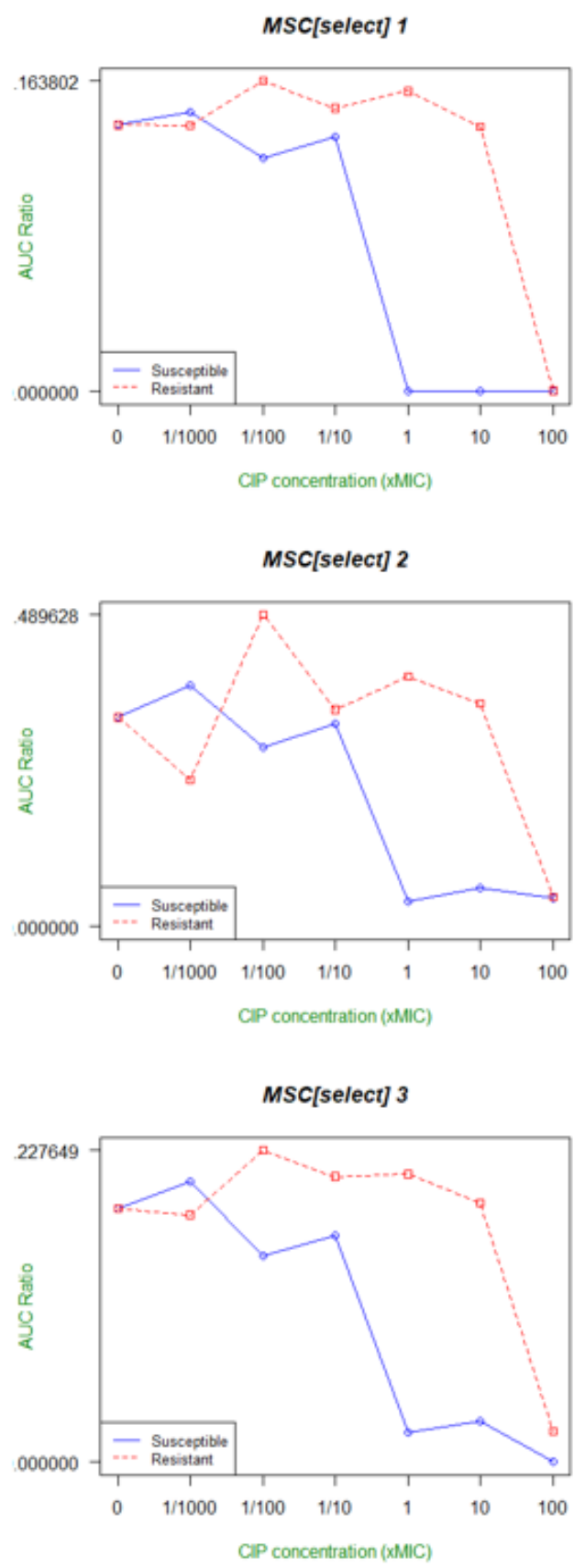
bioRxiv preprint doi: https://doi.org/10.1101/2021.06.03.446933; this version posted September 10, 2021. The copyright holder for this preprint (which was not certified by peer review) is the author/funder, who has granted bioRxiv a license to display the preprint in perpetuity. It is made available under aCC-BY-NC-ND 4.0 International license. 


\section{References}

1. Bash MC, Mcknew DL, Tapsall JW. Antibiotic Resistance in Neisseria. Antimicrobial Drug Resistance: Springer; 2009. p. 763-82.

2. Kenyon C, Buyze J, Wi T. Antimicrobial consumption and susceptibility of Neisseria gonorrhoeae: a global ecological analysis. Frontiers in medicine. 2018;5:329.

3. Kenyon C, Laumen J, Van Dijck C, De Baetselier I, Abdelatti S, Manoharan-Basil SS, et al. Gonorrhoea treatment combined with population-level general cephalosporin and quinolone consumption may select for Neisseria gonorrhoeae antimicrobial resistance at the levels of NG-MAST genogroup: an ecological study in Europe. J Glob Antimicrob Resist. 2020. Epub 2020/11/19. doi: 10.1016/j.jgar.2020.10.022. PubMed PMID: 33207228.

4. Spratt BG, Bowler LD, Zhang QY, Zhou J, Smith JM. Role of interspecies transfer of chromosomal genes in the evolution of penicillin resistance in pathogenic and commensal Neisseria species. J Mol Evol. 1992;34(2):115-25. Epub 1992/02/01. doi: 10.1007/BF00182388. PubMed PMID: 1556747.

5. Potts CC, Retchless AC, McNamara LA, Marasini D, Reese N, Swint S, et al. Acquisition of ciprofloxacin resistance among an expanding clade of $\beta$-lactamase positive, serogroup $Y$ Neisseria meningitidis in the United States. Clinical Infectious Diseases. 2021.

6. Chen $M$, Zhang $C$, Zhang $X$, Chen $M$. Meningococcal quinolone resistance originated from several commensal Neisseria species. Antimicrobial agents and chemotherapy. 2019.

7. Kenyon C, Manoharan-Basil SS, Van Dijck C. Gonococcal resistance can be viewed productively as part of a syndemic of antimicrobial resistance: an ecological analysis of 30 European countries. Antimicrob Resist Infect Control. 2020;9:97.

8. Gu B, Cao Y, Pan S, Zhuang L, Yu R, Peng Z, et al. Comparison of the prevalence and changing resistance to nalidixic acid and ciprofloxacin of Shigella between Europe-America and Asia-Africa from 1998 to 2009. Int J Antimicrob Ag. 2012;40(1):9-17.

9. Lu P-L, Liu Y-C, Toh H-S, Lee Y-L, Liu Y-M, Ho C-M, et al. Epidemiology and antimicrobial susceptibility profiles of Gram-negative bacteria causing urinary tract infections in the Asia-Pacific region: 2009-2010 results from the Study for Monitoring Antimicrobial Resistance Trends (SMART). Int J Antimicrob Ag. 2012;40:S37-S43.

10. Song J. Antimicrobial resistance control in Asia. AMR control. 2015:41-5.

11. Yam ELY, Hsu LY, Yap EP, Yeo TW, Lee V, Schlundt J, et al. Antimicrobial Resistance in the Asia Pacific region: a meeting report. Antimicrob Resist Infect Control. 2019;8:202. Epub 2020/01/01. doi: 10.1186/s13756-019-0654-8. PubMed PMID: 31890158; PubMed Central PMCID: PMCPMC6921568.

12. Fiore MA, Raisman JC, Wong NRH, Hudson AO, Wadsworth CB. Exploration of the Neisseria Resistome Reveals Resistance Mechanisms in Commensals That May Be Acquired by N. gonorrhoeae through Horizontal Gene Transfer. Antibiotics-Basel. 2020;9(10). doi: ARTN 656 10.3390/antibiotics9100656. PubMed PMID: WOS:000584161000001.

13. Shen YF, Chen ML. Prevalence, sequence type, and quinolone resistance of Neisseria lactamica carried in children younger than 15 years in Shanghai, China. Journal of Infection. 2020;80(1):61-8. doi: 10.1016/j.jinf.2019.08.020. PubMed PMID: WOS:000507459600008.

14. Yang Y, Liao MM, Gu WM, Bell K, Wu L, Eng NF, et al. Antimicrobial susceptibility and molecular determinants of quinolone resistance in Neisseria gonorrhoeae isolates from 
Shanghai. J Antimicrob Chemoth. 2006;58(4):868-72. doi: 10.1093/jac/dkl301. PubMed PMID: WOS:000240587400028.

15. Authority EFS. The European Union Summary Report on Antimicrobial Resistance in zoonotic and indicator bacteria from humans, animals and food in 2018/2019. Efsa J. 2021;19(4).

16. Muloi D, Ward MJ, Pedersen AB, Fevre EM, Woolhouse ME, van Bunnik BA. Are food animals responsible for transfer of antimicrobial-resistant Escherichia coli or their resistance determinants to human populations? A systematic review. Foodborne pathogens and disease. 2018;15(8):467-74.

17. Ben $\mathrm{Y}, \mathrm{Fu} \mathrm{C}$, Hu M, Liu L, Wong MH, Zheng $\mathrm{C}$. Human health risk assessment of antibiotic resistance associated with antibiotic residues in the environment: A review. Environ Res. 2019;169:483-93. Epub 2018/12/12. doi: 10.1016/j.envres.2018.11.040. PubMed PMID: 30530088.

18. Cantas L, Shah SQ, Cavaco LM, Manaia CM, Walsh F, Popowska M, et al. A brief multi-disciplinary review on antimicrobial resistance in medicine and its linkage to the global environmental microbiota. Front Microbiol. 2013;4:96. Epub 2013/05/16. doi: 10.3389/fmicb.2013.00096. PubMed PMID: 23675371; PubMed Central PMCID: PMCPMC3653125.

19. Răpuntean S, FiŃ N, Chirilă F, Nadăş G, Cosmina C, Călina D, et al. PHYSICAL FACTORS ACTION ON NEISSERIA SPP. STRAINS ISOLATED FROM ANIMALS. Bulletin UASVM. 2008;65:1. 20. Sneath $P$, Barrett $S$. A new species of Neisseria from the dental plaque of the domestic cow, Neisseria dentiae sp. nov. Letters in applied microbiology. 1996;23(5):355-8. 21. Kayalvizhi N, Anthony T, Gunasekaran P. Characterization of the Predominant Bacteria Associated with Sheep and Goat Skin. Journal of the American Leather Chemists Association. 2008;103(06):182-7.

22. Liu G, Tang CM, Exley RM. Non-pathogenic Neisseria: members of an abundant, multi-habitat, diverse genus. Microbiology (Reading). 2015;161(7):1297-312. Epub 2015/03/31. doi: 10.1099/mic.0.000086. PubMed PMID: 25814039.

23. Gullberg E, Albrecht LM, Karlsson C, Sandegren L, Andersson DI. Selection of a multidrug resistance plasmid by sublethal levels of antibiotics and heavy metals. MBio. 2014;5(5).

24. Stanton IC, Murray AK, Zhang L, Snape J, Gaze WH. Evolution of antibiotic resistance at low antibiotic concentrations including selection below the minimal selective concentration. Communications biology. 2020;3(1):1-11.

25. Gullberg E, Cao S, Berg OG, Ilbäck C, Sandegren L, Hughes D, et al. Selection of resistant bacteria at very low antibiotic concentrations. PLoS Pathog. 2011;7(7):e1002158.

26. Yang Y, Qiu W, Li Y, Liu L. Antibiotic residues in poultry food in Fujian Province of China. Food Addit Contam Part B Surveill. 2020;13(3):177-84. Epub 2020/04/21. doi: 10.1080/19393210.2020.1751309. PubMed PMID: 32308157.

27. Huang L, Mo Y, Wu Z, Rad S, Song X, Zeng H, et al. Occurrence, distribution, and health risk assessment of quinolone antibiotics in water, sediment, and fish species of Qingshitan reservoir, South China. Sci Rep. 2020;10(1):15777. Epub 2020/09/27. doi: 10.1038/s41598-020-72324-9. PubMed PMID: 32978412; PubMed Central PMCID: PMCPMC7519050.

28. Zheng $\mathrm{N}$, Wang J, Han $\mathrm{R}, \mathrm{Xu} \mathrm{X}$, Zhen $\mathrm{Y}, \mathrm{Qu} \mathrm{X}$, et al. Occurrence of several main antibiotic residues in raw milk in 10 provinces of China. Food Additives \& Contaminants: Part B. 2013;6(2):84-9. 
29. Wang Q-J, Mo C-H, Li Y-W, Gao P, Tai Y-P, Zhang Y, et al. Determination of four fluoroquinolone antibiotics in tap water in Guangzhou and Macao. Environmental Pollution. 2010;158(7):2350-8.

30. Ben $\mathrm{Y}, \mathrm{Hu} \mathrm{M}$, Zhang $\mathrm{X}, \mathrm{Wu} \mathrm{S}$, Wong MH, Wang $\mathrm{M}$, et al. Efficient detection and assessment of human exposure to trace antibiotic residues in drinking water. Water research. 2020;175:115699.

31. Kraupner N, Ebmeyer S, Hutinel M, Fick J, Flach CF, Larsson DGJ. Selective concentrations for trimethoprim resistance in aquatic environments. Environ Int. 2020;144:106083. Epub 2020/09/06. doi: 10.1016/j.envint.2020.106083. PubMed PMID: 32890888.

32. Gullberg E, Albrecht LM, Karlsson C, Sandegren L, Andersson DI. Selection of a multidrug resistance plasmid by sublethal levels of antibiotics and heavy metals. mBio. 2014;5(5):e01918-14. Epub 2014/10/09. doi: 10.1128/mBio.01918-14. PubMed PMID: 25293762; PubMed Central PMCID: PMCPMC4196238.

33. Verhoeven E, Abdellati S, Nys P, Laumen J, De Baetselier I, Crucitti T, et al. Construction and optimization of a 'NG Morbidostat'-An automated continuous-culture device for studying the pathways towards antibiotic resistance in Neisseria gonorrhoeae. F1000Research. 2019;8.

34. Laumen JGE, Manoharan-Basil SS, Verhoeven E, Abdellati S, De Baetselier I, Crucitti $\mathrm{T}$, et al. Molecular pathways to high-level azithromycin resistance in Neisseria gonorrhoeae. J Antimicrob Chemother. 2021;76(7):1752-8. Epub 2021/03/25. doi: 10.1093/jac/dkab084. PubMed PMID: 33760080.

35. Sprouffske K, Wagner A. Growthcurver: an R package for obtaining interpretable metrics from microbial growth curves. BMC Bioinformatics. 2016;17:172. Epub 2016/04/21. doi: 10.1186/s12859-016-1016-7. PubMed PMID: 27094401; PubMed Central PMCID: PMCPMC4837600.

36. Van Boeckel TP, Glennon EE, Chen D, Gilbert M, Robinson TP, Grenfell BT, et al. Reducing antimicrobial use in food animals. Science. 2017;357(6358):1350-2.

37. Wi T, Lahra MM, Ndowa F, Bala M, Dillon JR, Ramon-Pardo P, et al. Antimicrobial resistance in Neisseria gonorrhoeae: Global surveillance and a call for international collaborative action. PLoS Med. 2017;14(7):e1002344. Epub 2017/07/08. doi: 10.1371/journal.pmed.1002344. PubMed PMID: 28686231; PubMed Central PMCID: PMCPMC5501266.

38. Ji K, Kho Y, Park C, Paek D, Ryu P, Paek D, et al. Influence of water and food consumption on inadvertent antibiotics intake among general population. Environmental research. 2010;110(7):641-9.

39. Wang $\mathrm{H}$, Tang $\mathrm{C}$, Yang J, Wang N, Jiang F, Xia Q, et al. Predictors of urinary antibiotics in children of Shanghai and health risk assessment. Environment international. 2018;121:507-14.

40. Zhou YJ, Zhu F, Zheng DY, Gao MM, Guo BF, Zhang N, et al. Detection of antibiotics in the urine of children and pregnant women in Jiangsu, China. Environ Res. 2021;196:110945. Epub 2021/03/02. doi: 10.1016/j.envres.2021.110945. PubMed PMID: 33647296.

41. Wang Q, Duan YJ, Wang SP, Wang LT, Hou ZL, Cui YX, et al. Occurrence and distribution of clinical and veterinary antibiotics in the faeces of a Chinese population. J Hazard Mater. 2020;383:121129. Epub 2019/09/24. doi: 10.1016/j.jhazmat.2019.121129. PubMed PMID: 31546217. 
42. Ji K, Kho YL, Park Y, Choi K. Influence of a five-day vegetarian diet on urinary levels of antibiotics and phthalate metabolites: a pilot study with "Temple Stay" participants. Environmental research. 2010;110(4):375-82.

43. Prevention ECD, Prevention ECD, EFSA, EFSA, EMA. ECDC/EFSA/EMA second joint report on the integrated analysis of the consumption of antimicrobial agents and occurrence of antimicrobial resistance in bacteria from humans and food-producing animals: Joint Interagency Antimicrobial Consumption and Resistance Analysis (JIACRA) Report. Efsa J. 2017;15(7). doi: UNSP 4872 10.2903/j.efsa.2017.4872. PubMed PMID: WOS:000406685200007.

44. Thibaut Vanbaelen, Christophe Van Dijck, Jolein Laumen, Natalia Gonzalez, Irith De Baetselier, Sheeba S. Manoharan-Basil, et al. Global epidemiology of antimicrobial resistance in commensal Neisseria: a systematic review (In submission).

45. Klümper U, Recker M, Zhang L, Yin X, Zhang T, Buckling A, et al. Selection for antimicrobial resistance is reduced when embedded in a natural microbial community. The ISME journal. 2019;13(12):2927-37.

46. Murray AK, Stanton I, Gaze WH, Snape J. Dawning of a new ERA: Environmental Risk Assessment of antibiotics and their potential to select for antimicrobial resistance. Water Res. 2021;200:117233. Epub 2021/05/27. doi: 10.1016/j.watres.2021.117233. PubMed PMID: 34038824.

47. Kong FYS, Hatzis CL, Lau A, Williamson DA, Chow EPF, Fairley CK, et al. Treatment efficacy for pharyngeal Neisseria gonorrhoeae: a systematic review and meta-analysis of randomized controlled trials. J Antimicrob Chemother. 2020;75(11):3109-19. Epub 2020/08/05. doi: 10.1093/jac/dkaa300. PubMed PMID: 32747940.

48. de Block T, Laumen JGE, Van Dijck C, Abdellati S, De Baetselier I, Manoharan-Basil SS, et al. WGS of commensal Neisseria reveals acquisition of a new ribosomal protection protein (MsrD) as a possible explanation for high level azithromycin resistance in Belgium. Pathogens. 2021;10(3):384.

49. TPA, M SS, Jose A, Chandran L, Zachariah SM. Pharmacogenomics: the right drug to the right person. J Clin Med Res. 2009;1(4):191-4. doi: 10.4021/jocmr2009.08.1255. PubMed PMID: 22461867; PubMed Central PMCID: PMC3299179.

50. Rhodes K, Ma M, So M. A Natural Mouse Model for Neisseria Persistent Colonization. Methods Mol Biol. 2019;1997:403-12. Epub 2019/05/24. doi: 10.1007/978-1-4939-94960_23. PubMed PMID: 31119636; PubMed Central PMCID: PMCPMC6878645.

51. Ma M, Powell DA, Weyand NJ, Rhodes KA, Rendon MA, Frelinger JA, et al. A Natural Mouse Model for Neisseria Colonization. Infect Immun. 2018;86(5). Epub 2018/02/15. doi: 10.1128/IAI.00839-17. PubMed PMID: 29440372; PubMed Central PMCID: PMCPMC5913851.

52. FAO/WHO. Codex Alimentarius Commission (CAC): Maximum Residue Limits. Available from: http://www.fao.org/fao-who-codexalimentarius/codex-texts/maximumresidue-limits/en/.

53. European Comission. 37/2010. Commission Regulation (EU) No 37/2010 of 22 December 2009 on pharmacologically active substances and their classification regarding maximum residue limits in foodstuffs of animal origin. Off J Eur Union. 2010;15:1-72.

54. The European Agency for the Evaluation of Medicinal Products. COMMITTEE FOR VETERINARY MEDICINAL PRODUCTS: ENROFLOXACIN SUMMARY REPORT (2). 
bioRxiv preprint doi: https://doi.org/10.1101/2021.06.03.446933; this version posted September 10. 2021. The copvriaht holder for this preprint (which was not certified by peer review) is the author/funder, who has granted bioRxiv a license to display the preprint in perpetuity. It is made available under aCC-BY-NC-ND 4.0 International license.

55. Mitchell J, Griffiths M, McEwen S, McNab W, Yee A. Antimicrobial drug residues in milk and meat: causes, concerns, prevalence, regulations, tests, and test performance. Journal of food protection. 1998;61(6):742-56. 